University of Nebraska - Lincoln

DigitalCommons@University of Nebraska - Lincoln

Faculty Publications: Department of Teaching, Department of Teaching, Learning and Teacher Learning and Teacher Education

Education

2016

Personal Practical Knowledge of Teacher Educators

Vicki Ross

Elaine Chan

Follow this and additional works at: https://digitalcommons.unl.edu/teachlearnfacpub

Part of the Curriculum and Instruction Commons, and the Teacher Education and Professional

Development Commons

This Article is brought to you for free and open access by the Department of Teaching, Learning and Teacher Education at DigitalCommons@University of Nebraska - Lincoln. It has been accepted for inclusion in Faculty Publications: Department of Teaching, Learning and Teacher Education by an authorized administrator of DigitalCommons@University of Nebraska - Lincoln. 


\title{
Personal Practical Knowledge of Teacher Educators
}

\author{
Vicki Ross and Elaine Chan $†$ \\ * Department of Teaching and Learning, Northern Arizona University, \\ Flagstaff, AZ, USA; email Vicki.Ross@nau.edu \\ † Department of Teaching, Learning, and Teacher Education, \\ University of Nebraska-Lincoln, Lincoln, NE, USA; \\ email echan2@unl.edu
}

\section{Introductory Vignettes}

Seated in the front row of a crowded auditorium, we, Elaine and Vicki, listen to Dr. Jean Clandinin's (2015) address as she receives a Legacy - Lifetime achievement award from Division K of AERA. Jean recounts the early days of her academic career, sharing with us her experience as a beginning doctoral student reading about research on teachers and teaching. She tells us that she remembers feeling irate about how teachers were portrayed in the literature. Teachers she encountered in the research literature were presented as not knowing very much, and criticized for failing to fulfill their professional responsibilities of passing curriculum on to their students. This representation was at odds with her own experience working with teachers in schools. These tensions, in turn, formed the seeds of her career - long inquiry into the intersections of personal and professional experience in teaching.

For Vicki, a shift came as she read, in a 'Foundations of Curriculum' course, an article in which Kathy Carter (1990) critiques the portrayal of teachers in the existing research. Carter wrote of the kind and good, but hapless, teacher played off against the kind and good, and researcher - approved, teacher in studies that dot the education research field. This article, for Vicki, awakened the sense of how teachers are storied by others in the field of education research. The teacher in her sees this as an insidious device, structuring much of the reading she was doing in the field of mathematics education reform at the time. This kind of portrayal, she believes, dismisses the knowledge of teachers, and places researchers in a position of judgment over those in the field.

\footnotetext{
Published (as Chapter 15) in J. Loughran \& M.L. Hamilton (eds.), International Handbook of Teacher Education (Springer, 2016), pp. 3-33.

DOI 10.1007/978-981-10-0369-1_1

Copyright (C) 2016 Springer Science+Business Media Singapore. Used by permission.
} 
Elaine recalls feeling intimidated in doctoral classes as literature about the lives of teachers - a life she had lived herself as a classroom teacher - was discussed. At the time, Elaine did not feel adequately knowledgeable to contribute to discussions about the work of teaching despite the body of knowledge she had acquired through her own experience working in schools: she felt inadequate - silenced - and severed from her teacher knowledge/self. It was not until she found a space in the literature addressing the experiences of immigrant and minority students in North American schools that she found a place where her experiences could inform her later work with teachers as a teacher educator.

$\mathrm{T}$ hese vignettes capture tensions buried beneath the surface of the field of research focusing on teacher knowledge. These recollections provide an opening through which we introduce the notion of personal practical knowledge (PPK) and, then, explore complexities of knowledge and knowing in the lives and work of teacher educators. To do so, we draw heavily on existing literature based upon and addressing personal practical knowledge (Connelly \& Clandinin, 1988) to better understand tensions at play in the field of teacher knowledge, and to offer research literature and methods that value, document, and fold in details of teachers' experiences to inform understanding of the work of teacher educators.

We begin with a definition of the term 'personal practical knowledge', proposed by Connelly and Clandinin (1988), as an epistemological stance whereby teachers are recognized as knowing and knowledgeable. An epistemological stance wherein knowing is practical grounded in experience and best captured narratively. This stance conceives of teachers as both knowing and knowledgeable. Connelly and Clandinin (1988) argue in this framework that knowledge grows out of experience and that teachers construct knowledge through their interactions with students, teacher colleagues, parents, and others within and beyond their classroom and school contexts. This body of 'teacher knowledge' (Clandinin \& Connelly, 1996) gained through personal and professional experiences termed 'personal practical knowledge' (Connelly \& Clandinin, 1990) differs from the 'knowledge of teachers' (Clandinin \& Connelly, 1996) gained from expert sources such as professional documents and sources in that it is unique to the circumstances and contexts of each teacher. This conceptualization of teacher knowledge melds epistemology and ontology; thinking and being are intertwined within the individual, and grounded by 
the premise that who we are is what we know. Such knowing is visible in the stories teachers live, tell, retell, and relive in their classrooms (see Clandinin \& Connelly, 2000).

\section{Directions}

Our goal in this chapter is to review the development of the term personal practical knowledge as it emerged in research on teacher knowledge and their practical knowing of teaching. The chapter traces the avenues this has taken since its origin concept (its expansion and clarification as it has been applied in research). In particular, we examine and illuminate its applicability for capturing teachers' knowing in increasingly diverse school contexts. Finally, we turn to an exploration of the ways in which it has been applied to the knowledge of teacher educators.

First we underscore the value of teachers gaining an understanding of the term personal practical knowledge, and becoming wakeful to themselves as knowing and knowledgeable. We examine the development of this knowledge framework within the conversation of research on teaching and teacher education, specifically investigations focused on teacher knowledge, and explore ways in which ideas about teacher knowledge have shifted and changed across time and place. We consider personal practical knowledge as a lens through which scholars can develop deeper insights into, "the experiential, moral emotional, embodied knowledge teachers hold and express in their classroom practices" (Clandinin, Downey, \& Huber, 2009, p. 141). Such studies can be more carefully positioned to examine the tensions between teachers' knowledge (as it exists and as it develops) and the contexts in which teachers work. Conceiving of teacher knowledge in this way enables scholars to consider more carefully the "dialectic between each teachers' personal knowledge and his/her social contexts as knowledge shaped and lived out" (Clandinin et al., 2009, p. 141).

Personal practical knowledge was founded on Dewey's (1938) philosophy of experience particularly the interaction of the characteristics of continuity and the social in the development of knowing and acting on that knowing. Further, since teacher educators utilize their own personal practical knowing of teaching, specifically teaching teachers, 
then it would seem appropriate to extend this work to examine the personal practical knowledge of teacher educators which emerges in their own experience as teacher educators. In this process of developing personal practical knowledge as teacher educators, they draw upon their prior experiences and current practices within the context of their teacher education programs to inform their work with their education students (Clandinin et al., 2009).

We address connections of conceptions of personal practical knowledge to the work of teacher educators and the ways in which the notion of personal practical knowledge is presented in the teacher education literature. We also consider ways in which personal practical knowledge might inform teacher educators' work in preparing teachers for increasingly diverse school communities.

While much of the work featured in this chapter is set in a North American context, we are conscious of the ever-growing interconnections across global lines such that ideas about personal practical knowledge increasingly reflect nuances of cross-cultural influences. At the core of this examination of personal practical knowledge is our goal to better understand knowing and working as teachers and how teacher educators might draw upon this knowledge and develop their personal practical knowledge as teacher educators as a resource in teacher education.

\section{Importance of Teachers Having an Understanding of Personal Practical Knowledge}

As we noted in the above definition, Connelly and Clandinin (1988) conceived of personal practical knowledge as knowledge constructed from experience, and argued that teachers are knowing and knowledgeable persons. This notion challenged commonly-held beliefs of teacher knowledge at the time, which more often consisted of knowledge as held and created by others to be passed on from teachers to their students through the curriculum (see Brophy \& Good, 1986). At the time of Connelly and Clandinin's $(1986,1988)$ work on teacher knowledge as experientially based and expressed narratively, other conceptions of teacher thinking were also present which focused on categorizing the types of knowledge teachers held and used in practice (see Clark \& Peterson, 1986; Shulman, 1987). In contrast, Connelly and Clandinin, informed by Schwab's (1969, 1978) conception 
of the practical along with Lakoff and Johnson's (1980, 2003) work on embodied knowing, conceptualized teacher knowledge as holistic, embodied, and practical. Further, Personal practical knowledge was conceived of as constructed from a personal and practical base, utilized in creating curriculum with and for students within, but also beyond, the classroom and school contexts in which teachers live and work (e.g., Clandinin, 1985; Clandinin \& Connelly, 1995; Clandinin et al., 2006; Craig, 2003).

In this section of the chapter, we will underscore the significance and value that teachers derive from being able to conceptualize their knowing in this way with an understanding of the epistemological basis of their knowing (as practical, embodied, holistic, and emerging in the context of practice through sociality and continuity). The epistemological stance of this research is based in an orientation toward individual knowing and to ontology as the place from which productive inquiry into it and its development proceeds, particularly understanding experience and its contribution (see Clandinin \& Rosiek 2007) rather than on making claims for generalizable categorizations. Such understanding supports teachers in being wakeful to themselves as knowing and knowledgeable - as knowledge creators and producers and not just knowledge users. Through four avenues, we explore the importance of teachers' understanding personal practical knowledge, in that this conceptualization of teacher knowledge: (1) offers insights into curricular choices; (2) provides an explanation for differences in practices within milieus that enforce conformity and standardization; (3) counterbalances the emphasis on content knowledge, best practices, and other narrowed and categorical approaches to teacher knowledge and practices as trainable; and, (4) opens and connects avenues for understanding and developing more productive responses to the increasing diversity in classrooms and school communities.

\section{Personal Practical Knowledge Offers Insights into Curricular Choices of Teachers}

Built on our understandings of personal practical knowledge, we believe that recognizing the role of experience in shaping teachers' knowledge helps teachers to understand who they are and what they bring to the classroom. Their enriched understanding of experience 
in relation to curriculum and professional identity, in turn, informs their understanding of their curriculum practices and underlying philosophy. This exposure to and reflection upon the notion of personal practical knowledge deepens their understanding of their professional identity - who they are as educators and people and how they work and interact with their students.

Jean Clandinin's early research focused on examining details of teacher knowledge . Clandinin's inquiry into the mismatch between teachers' knowledge, as expressed in the literature she read as a doctoral student, and her own knowledge of teachers with whom she had worked as colleagues during her time as a school counselor, yielded an exploration of the complexities underlying teachers' work in schools that was, at the time, not widely recognized. She explored the notion of images and metaphors guiding the work of teachers through her detailed documentation of her teacher participant, Stephanie, whose teaching practices were guided by images of school and classroom as a home (Clandinin, 1986). Clandinin (1989) then went on to examine teachers' personal practical knowledge as reflecting 'rhythms' of events that may unfold over the course of a school day, week, year, term, and season in teaching.

Clandinin's writing highlighted ways in which the work of teachers intertwined with events that unfolded in their classroom and school community revealed their knowing and shifted and shaped it. This indepth examination of the work of teachers emphasized the complexity of teacher knowledge, and revealed the extent to which the body of knowledge from which teachers draw to inform their work with students is influenced and shaped by many factors within and beyond their school and classroom contexts.

Emerging from early work conducted by Elbaz (1981, 1983) and Clandinin (1986, 1989), the interconnections between teacher knowledge, identity, and curriculum are explored in further depth in two studies we highlight here. Tsui's (2004) case study of four secondlanguage teachers in a Hong Kong school illustrated the interplay between personal practical knowledge and curricular choices. This research was an examination of the professional development of these language teachers, each of whom were at varying levels of experience and, consequently, different levels of development and proficiency. The second study, also focused on language teachers, was an examination of the shaping influences of prior language-learning experiences 
on the classroom practice of three teacher participants in a school located in Turkey. Ariogul (2007) found that teachers' participation in a study focused on enhancing awareness of their own sense of teacher knowledge raised teachers' awareness of their teacher practices and decisions. One teacher in the study, for example, commented on how participation in the study helped her to better understand how she taught, who she was as a teacher, and what she wanted to accomplish in her teaching. These studies illustrate ways in which teachers' enriched understanding of their own personal practical knowledge contribute to deepening their insights into their curricular practices and their identity as teachers. As these kinds of studies demonstrate, when teachers uncover the specifics of their personal practical knowing as teachers, their practices become more refined, deliberate and focused and their teaching and confidence in it becomes stronger.

\section{Personal Practical Knowledge Offers an Explanation for Differences in Practices Within Milieus That Enforce Conformity and Standardization}

Standardization of expectations and outcomes for students, teachers, and schools is currently an often discussed theme in education research and literature. With the initiation and subsequent outcomes of 'Race to the Top,' we have curricula, materials, and resources that span across states. Teachers are frequently mandated and coerced into using these materials regardless of fit with the needs of children or how oppositional they are to the good practices of the teachers being forced to use these materials. With all the energy being applied to creating uniformity within the educational systems across the nation, it is puzzling that classrooms in Minnesota look different from classrooms in Arizona. Despite similarities from one classroom to the next from Massachusetts to California, for example, we nonetheless see differences in practice that undergird this imposed standard curriculum when we spend time in schools, even from fifth-grade classroom to fifth-grade classroom within the same school district or within the same school. We believe that the concept of teachers' personal practical knowledge, as organically connected to personal and practical experiences, offers insight into reasons for these differences.

From the early days of the process / product approach to curriculum, teachers have been storied as impediments to implementation 
of curriculum created by others outside the classroom (see Brophy \& Good, 1986). Those teachers, so the tale goes, cannot use curriculum with fidelity. What is lost in this approach to curriculum is the role that teachers' knowledge and identity play in the classroom. Teachers bring with them into their classrooms, their experiences as students (in K-12 public schools through university), their experiences as humans and their beliefs about what schools should look and feel like in addition to their practice, and their interactions with students - the compilation of these in the knowing and action of individual teachers is unique as is the personal and practical knowledge that shapes their work and they act in individualized ways.

Teachers may (and, we know many who do), quite rightly, chafe under a view of their work with curriculum development and enactment as being imposed from outside and designed as teacher proof. In similar ways to the problematic operationalization of such a curricular approach, the conceptualization of curriculum as outside the realm of teacher interpretation and adaptation is troubling, as well. Such a view of curriculum is dismissive of the work of teachers and their knowledge and their relational understanding of and commitment to the students they teach.

Clandinin (2013), in a recent work, reiterated the pivotal role of personal practical knowledge in the classroom lives of teachers. Her research highlighted the foundational place of 'image' in teacher knowledge, the argument we support; one tied to personal practical knowledge:

Teachers develop and use a special kind of knowledge. This knowledge is neither theoretical, in the sense of theories of learning, teaching, and curriculum, nor merely practical, in the sense of knowing children ... A teacher's special knowledge is composed of both kinds of knowledge, blended by the personal background and characteristics of the teacher, and expressed by her in particular situations. The idea of " image " is one form of personal practical knowledge, the name given to this special practical knowledge of teachers ... (Clandinin, 1985, p. 361)

When teachers and others understand the concept of teachers' personal practical knowledge as the knowing teachers draw on to guide 
their practice, teacher work, knowledge and curriculum making is strengthened and validated. Their work in classrooms is more accurately conceptualized as knowledgeable rather than improvisational or routine. Teachers benefit from seeing themselves as knowing and knowledgeable persons. Such a view can promote a reflective stance toward practice as opposed to enabling them to resist rather than acquiesce to the role of being implementers of an imposed generalizable curriculum. Conceptualizing teachers and teacher educators 'knowledge in this way (teacher educators are more able to attend to the "interwoven" nature of knowing teaching that exists (or could) between teachers and teacher education s) could therefore be more sustaining to both (Clandinin et al., 2009).

\section{Personal Practical Knowledge Counterbalances Emphasis on Content Knowledge, Best Practices, and Other Narrowed Approaches to Teacher Knowledge and Practices}

Scholars of education recognize teacher knowledge as an amalgam of indispensable, inseparable components. We argue that personal practical knowledge provides a vital complement to the more narrowed understandings of curriculum that shape the professional knowledge landscapes of teachers (Clandinin \& Connelly, 1995) and current practices of curriculum development as well. We describe this as an act of counterbalancing. We choose deliberately the idea of counter-balance. Funding is readily available to create professional development as well as canned curriculum targeting content areas, particularly in the STEM fields. Just as problematically based on evaluation of such canned approaches, researchers have embraced the idea of best practices. While these programs (professional development and curriculum programs that emerge) perhaps improve teacher quality in delivering content, certainly there are other important aspects of teacher knowledge, identity, and classroom practices that are of equal value. In addition, there is the matter of artful adjustment of pedagogy to ensure the individual advancement of particular children. These all might be considered under the umbrella of personal practical knowledge . Aspects such as knowledge of learners, pedagogy, classroom guidance, and relationships with parents are among topics that are certainly part of the holistic all-encompassing conceptualization of personal practical knowledge. Embedded in teachers' holistic, embodied practical 
knowing that guides them is also content knowledge, knowledge of content for teaching it, as well as best practices for developing thinking, speaking, reading, writing, listening and numeracy skills. Grossman and Shulman (1994) supported such a varied and rich understanding of the knowledge called upon by teachers in their practice:

At the heart of teachers' capacity to cope will be their developed pedagogical understanding, knowledge, and skills, and their dispositions and commitments regarding children, their subject matter, and the social conditions that surround both. (p. 18)

We acknowledge that content knowledge, pedagogical content knowledge, and a robust repertoire of teaching strategies are, of course, important aspects of a teacher's personal practical knowledge. We see points of intersection between personal practical knowledge and pedagogical content knowledge as put forward in the argument by Grossman and Shulman. In contrast to the argument for a category of teacher knowledge, personal practical knowledge highlights teacher knowing as experiential and holistic. In planning for teaching and enacting plans, teachers are simultaneously drawing on all aspects of their knowing rather than merely one component of it. Conceptualizing their knowing as personal, practical knowledge enables those who work to sustain teachers in their work and develop their practice and capacity as teachers, teacher educators are able to conceptualize better how to help teachers thrive in, rather than resist, professional development. This enables teacher educators to work more relationally in supporting teachers in teaching themselves to teach (see Clandinin et al., 2009).

\section{Personal Practical Knowledge Opens and Connects Ideas of Diversity in Classrooms and School Communities}

Understanding and building into teaching, learning, and curriculum the cultural, linguistic, socio-economic, sexual orientation, learning, abilities, racial, and gender diversity of members of the school community is a theme throughout education research and literature. There is an abundance of research highlighting the need for culturallyrelevant pedagogy (Ladson-Billings, 1995, 2001; Villegas, 1991) and 
culturally-sensitive curricula (Gay, 2000 /2010; Nieto \& Bode, 2012) that build on the experiences and knowledge that students of ethnicminority backgrounds bring to school contexts (Banks, 2015, Cummins, 2014; Igoa, 2007; Paley, 1979, 1995).

There are several externally-focused approaches, looking at resources, strategies, methods, and curricular approaches, presented to and for teachers. We believe that teachers' understanding of the concept of personal practical knowledge opens a more internally-focused approach. When teachers recognize the role of experience in shaping their knowledge and are encouraged to see the connection between who they are and what they bring to the classroom, they are more likely to then recognize and honor the way that students' experience infuses their identities as well. Chan's work in the area is an example we bring into this conversation.

Chan (2006), in her examination of teachers' experiences of culture in the curriculum, considered teachers' prior experiences in shaping their personal practical knowledge that in turn contributed to shaping their decisions about the design and implementation of curriculum for their students. The teachers featured in her study, drawing upon their experiences as students attending schools with little cultural diversity throughout their childhood, expressed a commitment to including, and celebrating, students' cultural backgrounds in their interactions with them in their diverse, urban middle school. One teacher was motivated by a desire to provide his students with opportunities to experience recreation activities that may be limited by their family's financial circumstances while the other teacher featured in the research was motivated to include outdoor education experiences for his seventh graders due to his previous, positive experience working with pre-teens on outdoor adventures. Both teachers expressed a commitment to supporting their students' participation in school curriculum activities. They only realized possible tensions associated with different ideas pertaining to gender equality in the implementation of curriculum activities when confronted with parents whose ideas about appropriate curriculum differed from those they had expressed for their male children.

Each student and teacher carries into their lives and work in school a unique way of knowing and being (Craig \& You, 2014; Lyons \& LaBoskey, 2002; Pinnegar \& Hamilton, 2009; Schlein \& Chan, 2013). Examination of their work highlighted the interconnections 
between teachers' prior experiences and their teacher knowledge, and ways in which they drew upon this body of knowledge to inform their curriculum decisions. In the process, nuances of the intersection between experience and teacher knowledge to inform curricular decisions were revealed. Examining details of how teachers drew upon their body of teacher knowledge to inform their work with their students opened up discussion about ideas of diversity in their classroom and school community, and raised questions about complexities of the role of teacher knowledge in contributing to teachers' curricular decisions. Teacher educators can be more proactive in drawing such knowledge into teacher candidates' experience in preparing to be teachers. In such work, teacher educators draw on their personal practical knowledge as teachers and as teacher educators (see Clandinin et al., 2009).

\section{Personal Practical Knowledge: Origins of an Idea and the Context of Its Growth and Development}

The concept of personal practical knowledge emerged from, and was embedded into, a program of research conducted in the early to mid1980 when a group of researchers at the Ontario Institute for Studies in Education, anchored by Michael Connelly, began exploring and developing a conceptualization of teacher knowledge that recognized teachers as 'knowledgeable and knowing' (Connelly \& Clandinin, 1988, p. 25). The early germination of this notion was found in the research and writing done by Elbaz (1981, 1983) and Dienes (Connelly \& Dienes, 1982). As the concept of teachers as creators of knowledge base $d$ in experience was taking shape, Clandinin's $(1985,1986)$ long-term, narrative inquiry work examining the classroom practices of an elementary teacher, Stephanie, shaped the concept further. This work offered a glimpse of the ways in which teachers' identity and experiences outside of the classroom may inform and shape their curricular decisions. This work offered insight into ways in which teachers make curricular decisions that are in turn connected to underlying knowledge gained through personal and practical experiences.

Clandinin's (1986) early work also pulled forward the concept of image as a knowledge construct. As we shared in the introductory vignette, Clandinin (2013) described her dissonance as a beginning 
doctoral student concerning the ways teachers were portrayed in the existing research literature. She referred to teachers with whom she had worked and knew of the care and consideration they took in making curricular decisions for their students. Their knowledge as teachers was grounded in their prior experiences with students, their own experiences as teachers and as learners, and their vision for what they wanted for their students and for themselves. This dissonance in the way that teacher knowledge was lived and the way it was portrayed in research inspired her to take a deeper look at the work of teachers. Thus, a program of research beginning with a study entitled the 'Personal Practical Knowledge Research Project,' was initiated.

Early in the project, attention was focused nearly exclusively on further exploration to deepen understanding of ways in which teacher knowledge may shape curriculum and classroom practice. Connelly and Clandinin's collaboration at Bay Street School was the context out of which a personal practical knowledge framework, as understood today, was developed. This conceptualization of personal practical knowledge (Connelly \& Clandinin, 1988) is grounded in the recognition of the influence of personal and professional experiences that shape teachers' curricular decisions and practice.

Over the course of the next three decades, the research sites shifted to include other schools and education contexts, other research team members, and a second research team as Clandinin established her Centre (Centre for Research on Teacher Education and Development) at another university. Throughout these changes, the focus on the collaborative development of the knowledge framework remained strong, as did the knowledge framework they had established. Their work acknowledges curriculum as constructed in the intersection of the personal practical knowledge of members of the school community, including administrators, students, and parents, and built on underlying notions of theory, practice and policy (see Clandinin \& Connelly, 1996; Connelly \& Clandinin, 1995).

Important to an understanding of the idea of personal practical knowledge, is the context from which it emanated and in which the idea was given scholarly consideration. A new way of understanding and thinking about teacher knowledge - personal practical knowledge - emerged from a field previously dominated by the idea of 'teacherproof' curriculum and a taken-for-granted understanding of teachers as consumers of others' knowledge. 
Connelly and Clandinin's (1988) conceptualization of personal practical knowledge is grounded in the recognition of the influence of personal and professional experiences. This knowledge shapes all of a teacher's doing and knowing - her curricular decisions, her teaching practices, her interactions with others (teachers, parents, administrators, community members and students). Connelly and Clandinin's work in this area is located in an understanding of curriculum as constructed in the intersection of between the personal and practical including not just the knowledge of teachers but also members of the school community, including administrators, students, and parents. Embedded in this knowing are teachers underlying notions, lived experience, and understanding of theory, practice and policy. Foundational to establishing an understanding of the term personal practical knowledge is a sketch of the context from which this notion of teacher knowledge finds its origins, and within which the idea was given scholarly consideration.

Emerging from a field of scholarship in education grounded in 'teacher -proof' curriculum and shaped by taken-for-granted understandings of teachers as consumers of others' knowledge, this period in the literature is sometimes referred to as the process -product approach to research in curriculum and teacher knowledge (for example, Brophy \& Good, 1986). In the decades stretching across the 1970s, 1980s, and 1990s, a shift in the field began to emerge with a focus on the knowledge used, held, and created by teachers. There was a shift toward the stance whereby teachers were viewed as knowing and knowledgeable and such knowing was embedded in the ontological (their relationships, practices, enactment of and planning for teaching and their action as teachers). This view developed in contrast to the previously accepted modernist epistemological paradigm where utilizing quantitative methods foundational claims for knowledge of teaching generalizable across contexts were made. Researchers' growing concern with teachers' individual knowing in thinking and practice, along with respect for that knowing, characterized by work such as that focused on personal practical knowledge sparked an epistemological challenge. As a result an important conversation within the community of educational researcher s and scholars ignited, and the multiple ways of understanding teacher knowledge stoked the literature. Several related, though distinct, approaches to studying teacher knowledge further fueled the development of a teacher knowledge framework. 
The teacher as researcher movement usually focused on the practice of action research as a way in which teachers could express their knowledge was reintroduced and expanded in this period (CochranSmith \& Lytle, 1993). Also working in the area of action research, although in a British context, Whitehead and McNiff (2006) used this approach of teachers studying their own practice around their experience of being 'living contradictions' (situations where they found their actions in practice to be in opposition to what they thought they were doing or their beliefs about practice). Whitehead and McNiff (2006) argued that such studies revealed 'living theories' - living because as they engaged in studying practice their knowing shifted and because it lived in the practices they studied. At the same time teacher educators were grappling with the idea of professional knowledge for teachers.

Tom and Valli (1990), in a chapter titled Professional for teachers, explored paradigms they felt shaped the ways in which teacher knowledge might be understood. Relevant to our work here, is the paradigm they proposed of 'craft', as seen in relation to positivistic, interpretive, and critical ways of seeing the world (work based in modernist epistemology), arguing that, “... classroom practitioners and some teacher educators continue to rely upon a craft conception of professional knowledge ; they seem to find little of generative or effective value in knowledge derived from the standard epistemological traditions" (p. 390). The notion of craft knowledge in teaching was explored further by Grimmett and MacKinnon (1992) and defined in their review of research in teacher knowledge. They argued for an understanding of teacher knowledge as, "a particular form of morally appropriate, intelligent, and sensible know-how that is constructed by teachers, holding progressive and radical educational beliefs, in the context of their lived experience s and work around issues of content -related and learner -focused pedagogy" (p. 396).

While Tom and Valli (1990) explored the teacher knowledge question through wrestling with paradigms, Carter (1990, p. 293) considered, "questions of what teachers know and how that knowledge is acquired" through a different kind of lens. As she examined the field of teacher knowledge, she saw three categories to help organize the work that was developing in the field at the time: 'teachers' information processing'; 'pedagogical content knowledge'; and, 'teachers' practical knowledge', which is where she felt there was a fit with the work built on the concept of personal practical knowledge. 
One of the three categories put forward by Carter (1990) in her review of the field was pedagogical content knowledge, a way of understanding the knowledge of teachers which had been put forward by Shulman (1987). In an encyclopedic summary of this construct by Grossman (1995), pedagogical content knowledge is presented as a part of a categorization of the knowledge of teachers. Pedagogical content knowledge, according to Grossman, was a combination of many types of knowledge that teachers create and use within their professional responsibilities. She listed six type of knowledge: knowledge of the content; knowledge of learners and learning; knowledge of general pedagogy; knowledge of curriculum; knowledge of context; and, knowledge of self. She referred to the phrase 'wisdom of practice' (Shulman, 2004) in talking about the knowledge of experienced teachers. Doyle (1990) added to this discussion, understanding the concept of teacher knowledge in a framework of decision-making. Richardson and Anders (1994) further used this framework to explore the notion of teacher knowledge as a changing and developing process.

Initially Fenstermacher (1986) explored teachers' knowledge as practical knowledge contrasting practical knowledge and propositional knowledge. Fenstermacher (1994) developed this idea further exploring these new, at the time, ways of understanding teacher knowledge. He set out a framework to categorize the, "epistemological character of what is and can be known by and about teachers and about teaching " (p. 5). His classification schemes set up boundaries, long-established in the field of philosophy and science, between formal knowledge and practical knowledge. His work offers a glimpse of the robust and exciting conversation about teacher knowledge in the field of education and curriculum at the time, showing that personal practical knowledge, as a way of thinking about teacher knowledge, was being explored and framed in the work of Connelly and Clandinin. Clandinin (1986), and Connelly and Clandinin (1988, 1990), shaped and added to this larger conversation that acknowledged the contribution of teachers' personal and professional experiences in shaping curriculum design and implementation in classrooms. Connelly and Clandinin's (1990) term personal practical knowledge offered insight into ways in which teachers' experiences, both personal and professional, may intersect in a classroom as teachers design, implement, and assess school curriculum. 
While these early expansions of the epistemological frame that set the conversation related to teacher knowledge were invaluable to its inception and development, the notion of personal practical knowledge really found a place in the field with the publication of Connelly and Clandinin's (1990) article and their foundational book, Teachers as curriculum makers: Narratives of experience (Connelly \& Clandinin, 1988). These contributions to the personal practical knowledge framework encompassed and built on Clandinin's (1986) work with Stephanie, the teacher participant from Bay Street School featured in this work. These early writings created a strong link, perhaps an unbreakable connection, between curriculum, defined as a 'life course' (Connelly \& Clandinin, 1988) and with narrative as both a phenomenon emerging from experience and as a methodology used to study experience.

The early work related to personal practical knowledge focused on teachers' classroom practices as the embodied knowing of teachers. The idea expanded from this beginning point to consider the ways that the contexts of schools and communities (Clandinin \& Connelly, 1995), as well as a host of other factors comprising the milieu of teachers, contributed this body of teacher knowledge. Current work, framed by the conception of personal practical knowledge, takes into account the knowing of the many stakeholders of curriculum, including students, their parents, and teacher educators.

\section{Personal Practical Knowledge of Students}

We present here research examining the personal practical knowledge of students (Chan, 2007, 2010). Chan's writing describing the experiences of immigrant and minority students in North American schools (Chan, 2007, 2010; Chan \& Schlein, 2010) contributes to a body of work introduced by Ayers and Schubert and recognized by Jackson in Pinar, Reynolds, Slattery, and Taubman's (1995), 'Understanding Curriculum', as 'student lore'. This, in turn, grows from Ayers and Schubert's body of work referred to as 'teacher lore', a collection of stories documenting the experiences of teachers as they work with their students in school.

This work developed in response to the need for, "information and awareness of the cultural backgrounds of pupils in order better to 
diagnose strengths, weaknesses, and differences in cognitive styles" (Moodley, 1995, p. 817) of a student population that is becoming increasingly diverse (LaBoskey, 2012; Schlein \& Chan, 2013). Despite existing research acknowledging the importance of home cultures and languages of diverse student populations in school contexts and the need to accommodate students through culturally sensitive and culturally relevant (Gay, 2000 /2010; Nieto \& Bode, 2012) curriculum, there seems to be little work focusing specifically on the experiences of immigrant and minority students, and even less examining in particular their experiences of participating in curriculum that is identified as culturally - sensitive. Much of the existing literature examining culturally sensitive curriculum is from a teacher perspective, illustrating ways in which students respond positively to initiatives to acknowledge or include their home cultures in school contexts. There is a general tendency to overlook student voice (Cook-Sather, 2002), and studies examining student response to school events, including examination of student voice and engagement in school reform, are relatively recent (Mitra, 2003, Rudduck, Chaplain, \& Wallace, 1996). Furthermore, there is in particular, a puzzling lack of research examining the curricular experiences of students of ethnic minority backgrounds from the perspective of the students themselves (Chan, 2007, He, Phillion, Chan, \& Xu, 2007).

Chan used a narrative inquiry approach (Clandinin \& Connelly, 1994, 2000), with a focus on 'stories of experience' (Connelly \& Clandinin, 1988) to learn about the experiences of immigrant and minority students as they interact and work with peers, teachers, and administrators in schools. Long-term, classroom -based participant observations were conducted at a diverse, urban elementary school, drawing on Jackson's (1990) work in 'Life in Classrooms'. This approach is in line with Dewey's (1938) theory of the interconnected-ness between education and experience, and Schwab's (1969) argument for the importance of focusing on the particular in curriculum development and implementation.

Chan's (2007) examination of students' experiences of culture in the curriculum raises questions about tensions when students respond to teacher initiatives to 'diversify' their curriculum in ways they had not anticipated. Chan (2010) also examines the experiences of immigrant and minority Chinese students as they balance affiliation to their ethnic, school, and neighborhood communities to address ways 
in which knowledge of home, community, culture, and life outside of school intersects with school curriculum, practices, and policies. For some students, the school curriculum may differ so significantly from what or how they are being encouraged to learn at home and in the community that curriculum in these two places may be viewed as 'conflicting stories to live by' (Chan, 2010). This work offers further evidence for the need for experiential research focusing specifically on exploring the intersection of home and school influences from the perspective of the students themselves. Knowledge gained about students' experiences of school curriculum stands to contribute significantly to the existing body of literature exploring the personal practical knowledge of teachers. This knowledge, appropriately identified as personal practical knowledge of students, acknowledges the complexities and richness of prior experiences in contributing and shaping future personal and professional experiences. In addition to learning about the students' experiences through participant observations conducted in a school research site where she was part of a research team who had been based in the school long term, and through ongoing informal interviews and conversations, Chan also drew upon her own experiences as a first-generation Chinese Canadian (Chan, 2003, 2010, 2015; Chan \& Boone, 2010) to inform her understanding of the interaction of culture and curriculum in schools.

\section{Curriculum of Lives in Transition}

Recent research raises questions about ways in which home curriculum might contribute to shaping the experiences of students further and more deeply at the family level in ways not previously considered when examining student knowledge. This knowledge contributes to learning in school as students bring to their school contexts knowledge shaped by prior experiences outside of school. Examination of the development of this personal practical knowledge offers a glimpse of a rich experience overlooked in school when considering what and how children acquire knowledge and a sense of identity in relation to their learning. This realization offers a glimpse into possibilities for deeper knowledge of students and their learning.

Examination of the details of students' experiences of curriculum within and beyond a school context offers a glimpse of the importance of these details in shaping the identity and knowledge of students 
(Chan, 2007, 2010; Clandinin et al., 2006, 2013; Huber, Murphy, \& Clandinin, 2011). Details of students' experiences as they move back and forth from home to school and then back again may be understood as an intersection of learning in the home and community, with learning through the school curriculum. Recognition of the interconnectedness between experience and education in this examination of the intersection of home and school learning is grounded in Dewey's (1938) work.

Recognizing these interconnections in learning, Huber et al. (2011) argued that understandings of curriculum should, appropriately, extend to learning that is experienced outside of school, such as in families and communities. They describe this work as 'a curriculum of lives' (Clandinin, Steeves, \& Caine 2013), to acknowledge the influences of family and community experiences in contributing to and extending the learning of children in ways much more complex than previously perceived. This strand of the research deliberately reaches beyond the walls of schools or classrooms to acknowledge and examine intersections of school and home curriculum by considering students' experience of curriculum in their home.

Shifting the focus to students and their families informs our understanding of the complexity of curriculum, by revealing the potential contribution of experiences beyond classrooms and schools to the school learning of students. This shift informs and enriches our understanding of the complexities of teaching and curriculum.

\section{Personal Practical Knowledge of Parents}

We consider next the personal practical knowledge of parents. Recognizing that students' experiences of curriculum and schooling may be shaped by personal practical knowledge developed through prior experiences, we are also extending this notion to parents (Nelson, 2014). Current school reform includes initiatives to engage parents in the schooling of their children. More specifically, there have been initiatives inviting parents into schools and encouraging parents to participate in school events, as well as to take leadership roles working with teachers and administrators in school councils or other parent groups within the school. Another venue receiving attention is the construction of and influence within and focused on teacher educators. 


\section{Personal Practical Knowledge of Teacher Educators: Meaning and Merit in Teacher Educators Having an Understanding of Personal Practical Knowledge}

Returning to the premise of personal practical knowledge as an epistemological stance whereby teachers are acknowledged as knowing and knowledgeable, and whereby knowledge is recognized as being constructed from experience, we use this knowledge framework as a lens to understand the work of teacher educators, and the interactions between them and their myriad contexts. Taking a logical next step, we argue that teacher educators are, first and foremost, teachers, who are also designing and implementing curriculum. We, too, are constructing knowledge from our experience. We, too, are knowing and knowledgeable. Teacher educators have a personal practical knowledge from which we operate and act. The interconnections between personal practical knowledge and teacher education stand to reason, given our assumptions related to the role of experience in shaping the work and lives of teachers and the professional decisions they make in their work with students in school. Implicit in these assumptions is the belief that our commitments and values are reflected in our work as teacher educators. The seemingly overlooked connection between personal practical knowledge and teacher education is puzzling; for this reason, we examine this relationship in further depth.

Next, we consider ways in which an understanding of the relationship between personal practical knowledge and the experiences of teachers may inform the work of teacher educators. Specifically, we begin by establishing a commonplaces framework to analyze personal practical knowledge of teacher educators. Then, we take this understanding of the interrelationships of these commonplaces one step further by considering ways in which a deepened apprehension and appreciation of personal practical knowledge of teacher educators stands to enrich their work with their education students.

\section{Commonplaces of Personal Practical Knowledge}

In establishing a conceptual framework to strengthen our understanding of the interconnections between personal practical knowledge and 
teacher education, we refer to Clandinin and Connelly's (2000) threedimensional narrative inquiry space to structure this exploration of personal practical knowledge and teacher education. First, we suggest that drawing connections between these two constructs may be a way to capture some of the complexities as various approaches to teacher education weave and intersect, and to outline boundaries on this wide-reaching concept of teacher knowledge as shaped by the experiences that educators bring to their curriculum work. Following this line of reasoning, Connelly and Clandinin (2006) argue that the temporal, social, and spatial dimensions of narrative inquiry (Clandinin \& Connelly, 2000) could also be considered commonplaces of narrative inquiry. We then propose an extension of this idea, and submit that the three dimensions of the narrative inquiry space could be conceived of as commonplaces of personal practical knowledge, as it relates to teacher education. Adapting the personal/social, spatial, and temporal commonplaces to explore personal practical knowledge in teacher education and teacher educators offers possibilities for addressing the puzzling gap between the abundance of research examining teacher knowledge - but which relies on implied connections to teacher education. When grounded in the concept of personal practical knowledge, those individuals who are engaged in teacher education embody personal practical knowledge as the foundation of their teacher education. Following this explanation of commonplaces for personal practical knowledge, we consider some of the existing work in which the concept of personal practical knowledge and teacher education are fused together.

Within this personal practical knowledge commonplace framework, Pinnegar and Hamilton (2012) explored their teaching practices as teacher educators, exposing and pursuing the following tendencies that seem to emerge in the practices of teacher educators (and narrative researchers):

- in moving field texts to research texts narrative researchers begin in the midst and naturally draw upon interpretive tools from other experiences in meaning-making;

- as the researchers attend to sociality, looking inward and outward, place and temporality slide naturally, fruitfully and tacitly into developing understandings; 
- in the perpetual motion of moving from internal/external, the researchers found themselves laying narratives alongside one another so that self is inextricably interwoven in process; and

- as analysis deepens, ethical issues regarding relationships between teachers, teacher educators, and the duty to unseen children emerge (Pinnegar \& Hamilton, 2012; in Chan, Ross, \& Keyes, 2012, p. xxv).

Pinnegar and Hamilton (2012) address in this exploration the extent of connections among the three dimensions despite their initial intention to focus in particular on the personal/social dimension in their work; in fact, they found that interconnections between all three dimensions were such that temporal and spatial dimensions could not be teased apart from the social-personal dimension they intended to examine in further depth. They found that:

... stories live alongside their meaning-making, and often the sense they make as a new story emerges through the provision of a different new story that repositions through plot, theme, and character the learning at which they arrive. Just as experience never ends and is only bounded for a particular interpretation, story escapes from analysis to assert meanings that remain open to restorying or the reconstruction of new understandings. (Chan et al., 2012, p. xxv)

We perceive in this example by Hamilton and Pinnegar the extent to which personal practical knowledge of a teacher educator is woven into the experiences of their students and develops alongside those of the people with whom a teacher educator interacts.

Following in this personal practical knowledge commonplace analysis, Keyes and Craig (2012) examined the influence of 'place' in the lives and work of teacher educators, exploring stories of tension and bumps on the professional landscape of teacher educators. They consider complexities that arise when, "the small stories that (teacher) educators live in relation to those far removed, authorized meta - narratives, and question how we can remain wakeful to the many story constellations of others that revolve around us?" (Chan et al., 2012, p. xxvi). Keyes and Craig address ways in which teacher educators' 
personal practical knowledge is woven into the meta-narratives of the place in which this knowledge and the associated stories develop and unfold.

Meanwhile, Murphy, Ross, and Huber (2012) pondered,

the relational nature of narrative inquiry and ways in which they became entangled in one another's knowing, and lives, through the sharing of stories. This beginning shaped the process as each author shared a story, followed by storied responses from co-authors. The commonplace of temporality (Connelly \& Clandinin, 2006) was strongly foregrounded in this relational process. The storytelling and response drew forward past narratives to respond to one another, as the authors simultaneously inquired into the shaping influence of these past experiences in the present "stories we live by" (Connelly \& Clandinin, 1999) as teacher educators.

The storied responses to one another's stories became layered one upon another. Evident to the authors was that they were also writing of sociality and place in their narratives despite their intention to focus on the temporal dimension. They were situated as narrative inquirers and teacher educators looking inward and outward as they took moments of personal significance and situated them in the context of social significance. Staying attentive to the commonplace of temporality helped them stay wakeful to how the past and future are understood in the context of the present. (Chan et al., 2012, p. xxvi)

Personal practical knowledge is represented in the past, present, and future interconnection and interrelationships alluded to in the work of Murphy, Ross, and Huber. Becoming cognizant of the interplay of temporal elements is fundamental to teacher educators' making meaning of the role that personal practical knowledge has in their lives and work preparing teachers.

Schlein and Chan (2012) refer to Clandinin and Connelly's (2000) notion of the three-dimensional narrative inquiry space to explore and to deliberate over ways in which culture may contribute to the interpretation of field texts when teachers are working with students of 
cultural backgrounds different from their own. They acknowledge the potential nuances of cross cultural influences that may further complicate interactions across dimensions of time, space, and sociality. Schlein and Chan (2012) highlighted the potential of drawing upon the narratives of teachers written in cultures and communities different from one's own, as resources for better understanding the development of personal practical knowledge in relation to experience. These chapters serve to illustrate some of the ways in which personal practical knowledge may be used by teacher educators to study their own lives and work. Next, we include examples of research and writing in which preservice students are encouraged to draw upon their prior experience to build a body of teacher knowledge that will in turn inform their future teaching. Although not stated explicitly, we believe these examples further communicate our point that teacher education is built on a bedrock of personal practical knowledge.

At one level, acknowledging the personal practical knowledge we hold as teacher educators calls us to explore and to understand the experiences that shape our practices and identities. Another aspect where we perceive connections between personal practical knowledge and teacher educators' lives and work is in the philosophical and curricular understandings we share with our preservice teachers. We argue for consideration of ways in which more explicit consideration of personal practical knowledge in teacher education would be beneficial. Samples of existing research that develop the rationale and methods of using personal practical knowledge with preservice teachers in their teacher education program follow. Conle et al. (2000) explored the potential influence of childhood personal experiences in contributing to the personal and professional knowledge of beginning teachers in a teacher education program in a Canadian context.

Built into coursework as discussion and research, preservice teachers inquired into the personal and professional experiences, to study how these interactions with diversity during schooling experiences might inform their knowledge about the experiences. This research supports the acknowledging of students' experiences as children that inform their understanding of their students of diverse backgrounds. A deeper understanding of the relationship between personal practical knowledge and teachers' curricular decisions and practices may inform teacher educators' work of preparing their preservice teachers 
for work in increasingly diverse classroom contexts. Learning about the experiences of others has the potential to highlight points in which we may find points of connection, as well as points of difference.

Conle et al. (2000) demonstrated the rich possibilities for teacher educators to draw upon their education students' diverse backgrounds and personal histories as resources for learning about ways in which experience may contribute to shaping teacher knowledge. This work is grounded in notions of the hermeneutic circle whereby students begin with an account of a story or interaction that grows with the responses of their classmates to their stories and interactions. Through the responses of their classmates, preservice teachers' understanding of experiences grow to include a wider and deeper understanding of the potential impact of individual past events of relevance to them about issues of diversity.

Conle's work illustrates ways in which personal practical knowledge is woven into preservice teachers' narratives such that the personal practical knowledge that develops across time, space, and through interaction with those in their personal and professional settings is, accordingly, interconnected. Experiences from which knowledge develops is deeply rooted and interconnected with new experiences that form the foundation on which teacher knowledge is based. Certainly, connections to teacher educators and their work in teacher education are evident, and from this illustration, we transition to explore the ways that personal practical knowledge can be used in teacher education for professional development.

\section{Recognizing How Personal Practical Knowledge May Be a Tool Used by Teacher Educators to Create Professional Development That Supports Teachers}

We hold that more explicit considerations of personal practical knowledge in teacher education would invigorate and strengthen our work and seems in many ways a natural development of previously published work addressing personal practical knowledge (Connelly \& Clandinin, 1988). Through recognition of the power of experience and the importance of understanding how experience informs our understanding of our identity and lives and work as teacher educators bridges our lives and work to the work and lives of teachers. 
This expanding of the understanding of personal practical knowledge into the professional development endeavors we undertake to support teachers is the next avenue we explore from and through the education research literature. The expansive nature of the notion of personal practical knowledge is embedded into this review of work in the area. This stretching of the construct, originally focused on the knowledge of teachers, now covers experiences lived by teachers, administrators, students, and parents within, as well as beyond, schools and classrooms and into communities and homes. Personal practical knowledge includes recognition of the more focused attention to the role of experience in shaping personal knowledge that may, in turn, inform personal professional knowledge in rich and nuanced ways.

As we considered the expansive nature of this term, we also noted more focused ways in which knowledge about personal practical knowledge has been recognized as contributing to the development of educators. We share, as an example, the work of teacher educators in Ed.D. programs associated with The Carnegie Program on the Education Doctorate (CPED), a more institutional approach to bringing the idea of practitioner knowledge to graduate work. Parallel to work in programs such as CPED, are examples of work at the graduate and undergraduate level to develop and understand how personal experience may shape teachers' professional identity. CPED, originated and developed by Shulman, is presented as a way of bridging the distance between teacher knowledge and teacher education. In this doctoral program, established practitioners examine their own practices and understanding of teaching and curriculum as the foundation for the coursework and doctoral dissertation research to complete their Ed.D. programs. Chan, Heaton, Swidler, and Wunder's (2014) piece and Chan's (2012) writing in Macintyre Latta and Wunder's (2012) book outlining ways in which CPED programs approached the work of 'placing practitioner knowledge at the center of teacher education' examined complexities that some of the Ed.D. students encountered when conducting research for their coursework and dissertation projects in their school sites. The need to better understand the notion of personal practical knowledge to inform teacher education and professional development is especially pronounced as teacher educators search for ways to support teachers in their professional development in an era of increasingly standardized approaches to curriculum, teaching, and learning. 


\section{Using Personal Practical Knowledge as Lens to Understand De- mands of Teacher Education Related to Increasingly Diverse Contexts}

Supporting teachers' professional development by and in studying their practices within their own school contexts represents one way that teacher educators may use the concept of personal practical knowledge to develop our work in schools with teachers. Another approach present in the research literature is to use personal practical knowledge of teachers as a point of connection to the diverse backgrounds and histories that students bring to the classroom.

Chan (2007) reinforced this idea when she examined students' responses to the inclusion of culture in the school curriculum. Students' responses revealed ways in which their interpretation attempts to be culturally sensitive through the implementation of school events to celebrate students' home cultures were interpreted in ways different than anticipated. The findings in these studies highlight the need to recognize diversity in ways that reflect goals and values of the students and teachers involved. This work also suggested that while teachers have personal practical knowledge that is shaped by their prior experiences, so, too, do students; finding ways to implement culturally-relevant curriculum for teachers may require further exploration to learn about this body of knowledge from the students, as well as a desire and willingness to learn about and consider these differences. The study highlighted complexities underlying notions of teacher knowledge of the interaction of curriculum implementation when teachers' experiences, that in turn shape their personal practical knowledge, intersect with the experience of their students to highlight nuances of curriculum design and implementation in ways not previously anticipated.

\section{Personal Practical Knowledge of Teacher Educators and Pragmatic Intellectual Space}

We consider next the potential of Schwab's (1959/1978) notion of the 'pragmatic intellectual space' as a space for recognizing the contribution of personal practical knowledge of teachers and others in school communities, and drawing upon this body of knowledge as a resource 
for examining complexities and nuances of a particular (Schwab, 1969 /1978) school community. We (Chan \& Ross, 2009, 2014) advocate for the implementation of pragmatic intellectual space in school communities to acknowledge knowledge of community members surrounding issues of relevance in schools, and recognizing the deliberative processes that occur within the intellectual space as professional development. We explore the potential of a 'pragmatic intellectual space' as a place where personal practical knowledge may form the foundation for teacher education. This framework, based on Schwab's notion of a 'pragmatic intellectual space' as a place where curriculum scholars may deliberate the complexities of curriculum, is a way of acknowledging the particular (Schwab, 1969 /1978).

We seek to further prior work to include teacher educators, who may guide preservice teachers to consider personal practical knowledge that informs teaching decisions in school contexts and classroom communities as being at the core of professional development that is highly relevant to their teaching practice in their own school communities. We consider Schwab's (1959/1978) notion of the 'pragmatic intellectual space' as a place in which ideas about events and interactions as they develop on a school landscape form the impetus for 'deliberations' (Schwab, 1983) among teachers to inform their understanding of teaching and learning in their 'particular' (Schwab, 1969 /1978) school community.

Elsewhere, we (Chan \& Ross, 2009, 2014; Ross \& Chan, 2008a, 2008b) explore Schwab's (1959 /1978) notion of the pragmatic intellectual space as a place in which ideas about events and interactions as they develop on a school landscape form the core of 'deliberations' (Schwab, 1969 /1978, 1973 /1978) among teachers to inform their understanding of teaching and learning in their 'particular' (Schwab, 1969 /1978) school community. Teachers were encouraged to draw upon the personal practical knowledge of members of the community to inform their understanding of events and complexities. We consider here the role of teacher educators in contributing to and supporting the development of a pragmatic intellectual space that reflects a personal practical knowledge. We consider ways in which teacher educators might guide pre-service teachers to envision teaching communities as pragmatic intellectual spaces that draw upon the personal practical knowledge of other members of the school community to inform their teaching decisions. Understanding teachers' personal 
practical knowledge as, perhaps, their most profound and meaningful professional resource acknowledges differences in perspective when teachers and students are interacting across differences in culture.

As we lead into the discussion of the development and possible future directions for research in the area of personal practical knowledge following examination of intersections of teacher education and diversity, as considered in existing work, Chan and Ross (2014) piece highlights the importance of deliberation and the potential of the Bay Street School community featured in their writing as a pragmatic intellectual space. In a similar vein, Clandinin et al. (2009), through the lens of their study of teachers who leave teaching, articulate the interwoven nature of teachers' and teacher educators' personal practical knowledge and the obligation teacher educators hold for living alongside teachers in ways that support them in developing knowing about teaching that will sustain them in their teaching.

We examine the relationship between personal practical knowledge and teacher education. We explore ways in which teacher educators, teachers, and pre-service teachers may use this notion, along with notions of 'particularity' (Schwab, 1969 /1978) and 'deliberation' (Schwab, 1983), as guiding principles for understanding classroom and school communities, and informing their teaching practice. We consider the potential of Schwab's (1959 /1978) notion of a 'pragmatic intellectual space' as a place where personal practical knowledge may form the foundation for teacher education.

We consider the role of teacher educators in contributing to and supporting a connection between personal practical knowledge and Schwab's (1959 /1978) notion of the 'pragmatic intellectual space'. We explore ways in which teacher educators, teachers, and pre-service teachers may use this notion, along with notions of 'particularity' (Schwab, 1969 /1978) and 'deliberation' (Schwab, 1973), as guiding principles for understanding classroom and school communities, and informing their teaching practice. Clandinin and Connelly (1992) emphasize the importance of examining the curriculum from the perspective of the teacher. They state,

Teachers and students live out a curriculum; teachers do not transmit, implement, or teach a curriculum and objectives; nor are they and their students carried forward in their work and studies by a curriculum of textbooks and content, 
instructional methodologies, and intentions. An account of teachers' and students' lives over time is the curriculum, although intentionality, objectives, and curriculum materials do play a part of it. (p. 365)

Paralleling the relationship between teacher experience and personal practical knowledge of teachers is the relationship between teacher educator experience and personal practical knowledge of teacher educators. While personal practical knowledge of teacher educators is an area in the field that seems to be in its early stages, we recognize the potential of this work to inform the work of teacher educators when preparing their preservice teachers for professional practice in complex settings.

\section{Personal Practical Knowledge: A Concept Rooted in International Education Contexts}

In thinking about how this idea of personal practical knowledge has been pulled into teacher education in helpful and positive ways, we feel it is incumbent upon us to acknowledge the many ways in which this concept has been and might be understood. Certainly, we see that coming to an understanding of an idea across cultural differences, as we find in a global perspective, shapes the construction of the experience that contributes to shaping teacher knowledge. Throughout this chapter, we have considered ways in which different cultures may understand personal practical knowledge in different ways. We share some of the existing literature to offer a glimpse of how the notion of personal practical knowledge of educators may be understood and expressed differently in different places around the world.

As in teacher education in a North American context, the concept of personal practical knowledge is used in three basic ways in contexts around other geographical regions and other cultural settings. Personal practical knowledge can be seen as a tool used by those in teacher education for the purpose of teacher professional development. It may be a means of working with preservice teachers, either to encourage them to understand their teacher identity or the continuities of experience that their students bring with them into the classroom. The third way that the idea of personal practical knowledge is 
used in teacher education is as a way of understanding the lives and work of teacher educators.

Earlier in this chapter, we shared two studies in which practicing, experienced (to more or lesser degrees), teachers, as participants in research were involved in using personal practical knowledge in ways designed to help them understand their classroom practices. Combining the Ariogul (2007) study with Tsui's (2004) investigation with another international use of personal practical knowledge captures how this idea has been transplanted and rooted within other geographical and cultural contexts. To reiterate, in each of these three examples, personal practical knowledge is used as a tool for professional development for practicing teachers who are at varying levels of experience. The role of the investigator is unclear as to whether these individuals are engaging in these projects within a role of teacher educator, or as education researcher, or both. That being said, in a third example of personal practical work in teacher education with experienced teachers found in an international context, this knowledge framework was used in a professional development program with 14 early childhood teachers in Australia. Black (2002) reported on the four month intervention study that collected metaphors, drawings, personal writing, and conversations. The methods used to access personal practical knowledge of these teacher participants was termed 'cycles of reflective inquiry'. Kim, whose work was the data presented in the articles, reflecting in the understandings she took away from this personal practical knowledge work reported:

I have really examined how I feel about what I am doing. This has been helpful in clarifying my goals and aims as a teacher and for my future. Having the opportunity to talk to others has helped me feel that I am not along and that teaching in childcare is challenging in many ways. (Black, 2002, p. 84)

Similarly, these shared sentiments are expressed by a teacher participant in the Ariogul (2007) study. Using personal practical knowledge as a way of helping teachers study and appreciate the knowledge base from, and in which, they are constructing and reconstructing knowledge is borne out in these international contexts. 
The second way that personal practical knowledge is used in international contexts of teacher education is with preservice teachers. As with the studies involving practicing, experienced teachers, this concept is seen as a tool for self-exploration and understanding the contexts of practice in which they plan to work. We provide one example of this kind of study. Using this knowledge framework in quite a different approach, Tsang (2004) looked for connections between the utilizations of personal practical knowledge of preservice teachers, which was operationalized as teaching maxims, and their interactive decisions. This research concludes that personal practical knowledge can be at odds with decision in the classroom and that the knowledge held by teachers is complex and complicated. Direct relationships between beliefs and actions are sometimes elusive. The relationship between knowledge and practice is blurred. This study is an interesting documentation of personal practical knowledge in teacher education. In the research the focus is on studying its place in the work of beginning teachers rather than in the lives and work of practicing teachers.

Then, as in a North American context, we find that teacher educators, internationally, find personal practical knowledge a helpful tool to use to examine their own practice. The research we present as an example bridges these two approaches, that is as a tool for work with teachers and as a means for self- reflection and development, but it also incorporates work with graduate students as well. From the outset, the term, personal practical knowledge, was bound to narrative inquiry, experience, teacher knowledge, and an understanding of curriculum as a life course. We explore the work of Elbaz-Luwisch, whose early work was foundational to the development of this conceptualization of teacher knowledge. Throughout her numerous publications, a unifying, continued reliance on and building upon the central tenets established in the 1980 s research with her participant, Sarah, about whom she wrote in a foundational article, The teacher's 'practical knowledge': Report of a case study (Elbaz, 1981), and in a book entitled, Teacher thinking: A study of practical knowledge (Elbaz, 1983). Elbaz-Luwisch has many publications, but here, the focus in this review is placed on her most recent, Auto / biography and pedagogy: Memory and presence in teacher (2013).

In this latest development of her thinking, Elbaz -Luwisch, who has in other research focused on teachers and teacher education, turns the 
inquiry inward to an examination of her autobiography. She traces her family histories as European Jews immigrating to Canada, Israel, and elsewhere in the years leading up to World War II. Through her personal exploration, Elbaz-Luwisch examines her mother's life and teachings, intimately connecting both with her work as a teacher educator. She examines these same powerful forces in her life with teachers and graduate students at her university, with the eye toward understanding how these understandings and stories infuse individuals' classrooms and school lives. In the final section of this book, ElbazLuwisch and her research participants study the experience of situating personal knowledge within contexts very different from ones in which the knowledge was constructed. Moving accounts are woven together through and with the deep and broad theoretical tapestry Elbaz-Luwisch creates in this book.

This compelling theme of transposing knowledge constructed within one context to another is echoed in other cross-cultural work featured here. The first is a study situated in Hong Kong conducted by Harfitt and Gram (2015), and the second is one conducted by Schlein (2010). Harfitt and Gram's work examining tensions described by experienced teachers from the United Kingdom when they assumed teaching positions in Hong Kong schools as 'expert' teachers suggested underlying differences in ideas about teacher knowledge. The tensions in teacher knowledge, when experienced teachers from places outside of Hong Kong are hired to teach in Hong Kong schools, illustrates the power of context in shaping ideas about teaching. Expectations that their knowledge as experienced teachers would transfer easily into a Hong Kong context contributed to tensions in their work as they interacted and collaborated with their Hong Kong colleagues in school.

Research offering insights into interpretation of teacher knowledge cross-culturally and/or interculturally, as is done in Schlein's (2010) work, informs our understanding of ways in which knowledge about teaching in places beyond our own enriches our knowledge and potentially informs our work in teacher education.

\section{Conclusion}

This brief examination of the development of the concept of personal practical knowledge of teachers and teacher educators in an 
international context captures the essence of the notion of personal practical knowledge through its emphasis on the potential of this term to inform our understanding of the work of teachers. Our goal throughout this chapter has been to acknowledge the knowledge of teachers, to better understand the work of teachers, and to draw upon this knowledge as a resource for teacher education. Tracing the development of the term in the field of teacher knowledge provided a glimpse of the context in which recognition of the knowledge of teachers was established, and reasons for which it might have been a challenge to develop. As ideas about personal practical knowledge of teacher educators continues to grow, we are reminded of its potential as a resource for informing professional development for teachers, as well as highlighting possibilities for supporting further work on personal practical knowledge in North America and beyond.

\section{References}

Ariogul, S. (2007). Understanding foreign language teachers' practical knowledge: What's the role of prior language learning experience? Journal of Language and Linguistic Studies, 3 (1), 168-181.

Banks, J. A. (2015). Multicultural education, school reform, and educational equality. In The Equity Project (Ed.), Opening the doors to opportunity for all: Setting a research agenda for the future (pp. 54-63). Washington, DC: American Institutes of Research.

Black, A. L. (2002). Making sense of what it means to teach: Artful representations as meaning-making tools. Teacher Development, 6 (1), 75-88. doi: 10.1080/13664530200200158.

Brophy, J., \& Good, T. (1986). Teacher behavior and student achievement. In M. Wittrock (Ed.), Handbook of research on teaching (3rd ed., pp. 328-375). New York: MacMillan Publishing Company.

Carter, K. (1990). Teachers' knowledge and learning to teach. In R. Houston (Ed.), Handbook of research on teacher education: A project of the association of teacher educators (pp. 291-310). New York: Macmillan Publishing Company.

Chan, E. (2003). OP-ED. Ethnic identity in transition: Chinese new year through the years. Journal of Curriculum Studies, 35 (4), 409-423.

Chan, E. (2006). Teacher experiences of culture in the curriculum. Journal of Curriculum Studies, 38 (2), 161-176.

Chan, E. (2007). Student experiences of a culturally-sensitive curriculum: Ethnic identity development amid conflicting stories to live by. Journal of Curriculum Studies, 39 (2), 177-194. 
Chan, E. (2010). Living in the space between participant and researcher: Examining ethnic identity of Chinese Canadian students as a narrative inquirer. The Journal of Educational Research, 102 (2), 113-122.

Chan, E. (2012). From teacher to researcher, researcher to teacher: Examining educators' experiences of conducting research. In M. Macintyre Latta \& S. Wunder (Eds.), Placing practitioner knowledge at the center of teacher education-rethinking the policy and practice of the education doctorate (pp. 179-197). Charlotte, NC: Information Age Press.

Chan, E. (2015). "An interesting time in my life". Balancing culture with curriculum for a Chinese middle school student. Journal of Family Diversity in Education. Special Issue: Curriculum Making with Diverse Children, Families and Teachers, 1 (3), 33-50.

Chan, E., Heaton, R. M., Swidler, S. A., \& Wunder, S. (2014). Examining CPED cohort dissertations: A window into the learning of Ed.D. students. Planning and Changing CPED Special Issue: The Education Doctorate, a Degree for Our Times, $44(3 / 4)$.

Chan, E., \& Boone, M. (2010). Addressing multicultural issues through teacher stories. In T. Huber-Warring (Series Ed.), Storied inquiries in international landscapes: An anthology of educational research. Teaching learning indigenous, intercultural worldviews: International perspectives on social justice and human rights (Vol. 3, pp. 265-272). Charlotte, NC: Information Age Publishing.

Chan, E., \& Ross, V. (2009). Examining teachers' knowledge on a landscape of theory, practice, and policy. Curriculum and Teaching Dialogue, 11 (1 \& 2), 159-171.

Chan, E., \& Ross, V. (2014). Narrative understandings of a school policy: Intersecting student, teacher, parent, and administrator perspectives. Journal of Curriculum Studies, 46 (5), 656-675.

Chan, E., Ross, V., \& Keyes, D. (Eds.). (2012). Narrative inquirers in the midst of meaning-making: Interpretive acts of teacher educators. Bingley, UK: Emerald Group Publishing Limited.

Chan, E., \& Schlein, C. (2010). Supporting Muslim students in a secular public school. Diaspora, Indigenous, and Minority Education: An International Journal, 4, 253-267.

Clandinin, D. J. (1985). Personal practical knowledge: A study of teachers' classroom images. Curriculum Inquiry, 15 (4), 361-385.

Clandinin, D. J. (1986). Classroom practice: Teacher images in action. Barcombe Lewes, UK: Falmer Press.

Clandinin, D. J. (1989). Developing rhythm in teaching: The narrative study of a beginning teacher's personal practical knowledge of classrooms. Curriculum Inquiry, 19 (2), 121-141.

Clandinin, D. J. (2013). Huberman award acceptance speech. Lives of teachers special interest group. American Educational Research Association Annual Meeting, San Francisco. 
Clandinin, D. J., \& Connelly, F. M. (1992). Teacher as curriculum maker. In P. W. Jackson (Ed.), Handbook of curriculum (pp. 363-401). New York: Macmillan.

Clandinin, D. J., \& Connelly, F. M. (1994). Personal experience methods. In N. K. Denzin \& Y. S. Lincoln (Eds.), Handbook of qualitative research in the social sciences (pp. 413-427). Thousand Oaks, CA: Sage.

Clandinin, D. J., \& Connelly, F. (1995). Teachers' professional knowledge landscapes. New York: Teachers College Press.

Clandinin, D. J., \& Connelly, F. (1996). Teachers professional knowledge landscapes: Teacher stories - Stories of teachers - School stories - Stories of schools. Educational Researcher, 25 (3), 24-30.

Clandinin, D. J., \& Connelly, F. M. (2000). Narrative inquiry: Experience and story in qualitative research. San Francisco: Jossey-Bass Publishers.

Clandinin, D. J., Downey, C. A., \& Huber, J. (2009). Attending to changing landscapes: Shaping the interwoven identities of teachers and teacher educators. Asia-Pacific Journal of Teacher Education, 37 (2), 141-154.

Clandinin, D. J., Huber, J., Huber, M., Murphy, M. S., Murray Orr, A., Pearce, M., et al. (2006). Composing diverse identities: Narrative inquiries into the interwoven lives of children and teachers. New York: Routledge.

Clandinin, D. J., \& Rosiek, J. (2007). Mapping a landscape of narrative inquiry: Borderland spaces and tensions. In D. J. Clandinin (Ed.), Handbook of narrative inquiry: Mapping a methodology (pp. 35-76). Thousand Oaks, CA: Sage.

Clandinin, D. J., Steeves, P., \& Caine, V. (2013). Composing lives in transition: A narrative inquiry into the experiences of early school leavers. Volume 16, Advances in research on teaching series. Bingley, UK: Emerald Group Publishing Ltd.

Clark, C., \& Peterson, P. (1986). Teacher thought processes. In M. Wittrock (Ed.), Handbook of research on teaching (3rd ed., pp. 255-296). New York: MacMillan Publishing Co.

Cochran-Smith, M., \& Lytle, S. L. (1993). Inside/outside: Teacher research and knowledge. New York: Teachers College Press.

Conle, C., Blanchard, D., Burton, K., Higgins, A., Kelly, M., Sullivan, L., et al. (2000). The asset of cultural pluralism: An account of cross-cultural learning in pre-service teacher education. Teaching and Teacher Education, 16, 365-387.

Connelly, F. M., \& Clandinin, D. J. (1988). Teachers as curriculum planners: Narratives of experience. New York: Teachers College Press.

Connelly, F. M., \& Clandinin, D. J. (1990). Stories of experience and narrative inquiry. Educational Researcher, 19 (5), 2-14.

Connelly, F. M., \& Clandinin, D. J. (1995). Teachers' professional knowledge landscapes. New York: Teachers College Press.

Connelly, F. M., \& Clandinin, D. J. (1999). Stories to live by: Teacher identities on a changing professional knowledge landscape. In F. M. Connelly \& D. J. Clandinin (Eds.), Shaping a professional identity: Stories of educational practice (pp. 114132). London: The Althouse Press: Faculty of Education, The University of Western Ontario. 
Connelly, F. M., \& Clandinin, D. J. (2006). Narrative inquiry. In J. Green, G. Camilli, \& P. Elmore (Eds.), Handbook of complementary methods in educational research (pp. 477-489). Washington, DC: American Educational Research Association.

Connelly, F. M., \& Dienes, B. (1982). Teacher's role in curriculum planning: A case study. In K. Leithwood (Ed.), Studies in curriculum decision making (pp. 183198). Toronto, Canada: Ontario Institute for Studies in Education.

Cook-Sather, A. (2002). Authorizing students' perspectives: Toward trust, dialogue, and change in education. Educational Researcher, 31, 3-14.

Craig, C. J. (2003). Narrative inquiries of school reform: Storied lives, storied landscapes, storied metaphors. Greenwich, CN: Information Age Publishing.

Craig, C., \& You, J. A. (2014). Pedagogy through the pearl metaphor: Teaching as a process of ongoing refinement. Paper presented at the American Educational Research Association Annual Meeting, Philadelphia.

Cummins, J. (2014). Language and identity in multilingual schools: Constructing evidence-based instructional policies. In D. Little, C. Leung, \& P. Van Avermaet (Eds.), Managing diversity in education: Languages, policies, pedagogies (pp. 3-26). Toronto, Canada: Multilingual Matters.

Dewey, J. (1938). Experience and education. New York: Simon and Schuster.

Doyle, W. (1990). Themes in teacher education research. In W. R. Houston (Ed.), Handbook of research on teacher education: A project of the association of teacher educators (pp. 3-24). New York: McMillan.

Elbaz, F. (1981). The teacher's 'practical knowledge': Report of a case study. Curriculum Inquiry, 11 (1), 43-71.

Elbaz, F. (1983). Teacher thinking: A study of practical knowledge. London: Croom Helm.

Elbaz-Luwisch, F. (2013). Auto/biography \& pedagogy: Memory \& presence in teaching (complicated conversation, a book series of curriculum). New York: Peter Lang.

Fenstermacher, G. D. (1986). Philosophy of research on teaching: Three aspects. In M. C. Wittrock (Ed.), Handbook of research on teaching (3rd ed., pp. 37-49). New York: Macmillan.

Fenstermacher, G. D. (1994). The knower and the known: The nature of knowledge in research on teaching. In L. Darling-Hammond (Ed.), Review of research in education (pp. 3-56). Washington, DC: American Educational Research Association.

Gay, G. (2000/2010). Culturally responsive teaching: Theory, research and practice. New York: Teachers College Press.

Grimmett, P. P., \& MacKinnon, A. M. (1992). Craft knowledge and the education of teachers. In L. Darling-Hammond (Ed.), Review of research in education (pp. 385-456). Washington, DC: American Educational Research Association.

Grossman, P. (1995). Teachers' knowledge. In L. Anderson (Ed.), The encyclopedia of teaching and teacher education (2nd ed., pp. 20-24). Oxford, UK: Elsevier Science Ltd. 
Grossman, P. L., \& Shulman, L. S. (1994). Knowing, believing, and the teaching of English. In T. Shanahan (Ed.), Teachers thinking, teachers knowing: Reflections on literacy and language education (pp. 3-22). Urbana, IL: National Conference of Research on English.

Harfitt, G. J., \& Gram, N. (2015). "A small eddy in a large river": the first year experiences of native English-speaking teachers abroad. Paper presented at the annual conference of the American Educational Research Association.

He, M. F., Phillion, J., Chan, E., \& Xu, S. (2007). Immigrant students' experience of curriculum. In F. M. Connelly, M. F. He, \& J. Phillion (Eds.), Handbook of curriculum and instruction (pp. 219-239). Thousand Oaks, CA: Sage.

Huber, J., Murphy, M. S., \& Clandinin, D. J. (2011). Places of curriculum making: Narrative inquiries into children's lives in motion. Volume 14, advances in research on teaching series. Bingley, UK: Emerald Group Publishing Ltd.

Igoa, C. (2007). Immigrant children: Art as a second. In S. Books (Ed.), Invisible children in the society and its schools (3rd ed., pp. 117-140). London:

Routledge.

Jackson, P. W. (1990). Life in classrooms. New York: Teachers College Press.

Keyes, D., \& Craig, C. (2012). Burrowing and broadening in the storied place in teacher education. In E. Chan, V. Ross, \& D. Keyes (Eds.), Narrative inquirers in the midst of meaning-making: Interpretive acts of teacher educators (pp. 2349). Bingley, UK: Emerald Group Publishing Limited.

LaBoskey, V. (2012). The ghost of social justice education future: How the worlds of graduates contribute to the self-transformation. Studying Teacher Education, 8 (3), 227-244. doi: 10.1080/17425964.2012.720929.

Ladson-Billings, G. (1995). Multicultural teacher education: Research, practice, and policy. In J. A. Banks \& C. A. McGee Banks (Eds.), Handbook of research on multicultural education (pp. 747-759). Toronto, Canada: Prentice Hall International.

Ladson-Billings, G. (2001). Crossing over to Canaan: The journey of new teachers in diverse classrooms. San Francisco: Jossey-Bass.

Lakoff, G., \& Johnson, M. (1980/2003). Metaphors we live by. Chicago: University of Chicago Press.

Lakoff, G., \& Johnson, M. (2003). Metaphors we live by. Chicago: University of Chicago Press.

Lyons, N., \& LaBoskey, V. K. (Eds.). (2002). Narrative knowing in teaching: Exemplars of reflective teaching, research, and teacher education. New York: Teachers College Press.

Macintyre Latta, M., \& Wunder, S. (Eds.). (2012). Placing practitioner knowledge at the center of teacher education-rethinking the policy and practice of the education doctorate. Charlotte, NC: Information Age Press.

Mitra, D. L. (2003). Student voice in school reform: Reframing student-teacher relationships. McGill Journal of Education, 38 (2), 289-304. 
Moodley, K. A. (1995). Multicultural education in Canada: Historical development and current status. In J. A. Banks \& C. A. McGee Banks (Eds.), Handbook of research on multicultural education (pp. 801-820). Toronto, Canada: Prentice Hall International.

Murphy, S., Ross, V., \& Huber, J. (2012). Attending to the temporal dimension of narrative inquiry into teacher educator identities. In E. Chan, V. Ross, \& D. Keyes (Eds.), Narrative inquirers in the midst of meaning-making: Interpretive acts of teacher educators (pp. 51-75). Bingley, UK: Emerald Group Publishing Limited.

Nelson, J. B. (2014). Teaching and learning through multiple lenses: Educator/ parents problematizing schooling via their students and their own children. Paper presented at the American Educational Research Association Annual Meeting, Philadelphia.

Nieto, S., \& Bode, P. (2012). Affirming diversity: The sociopolitical context of multicultural education (6th ed.). New York: Longman.

Paley, V. G. (1979). White teacher. Cambridge, MA: Harvard University Press.

Paley, V. G. (1995). Kwanzaa and me: A teacher's story. Cambridge, MA: Harvard University Press.

Pinar, W. F., Reynolds, W. M., Slattery, P., \& Taubman, P. M. (1995). Understanding curriculum: An introduction to the study of historical and contemporary curriculum discourses. New York: Peter Lang.

Pinnegar, S., \& Hamilton, M. L. (2009). Self-study of practice as a genre of qualitative research: Theory, methodology, and practice. Dordrecht, Netherlands: Springer.

Pinnegar, S., \& Hamilton, M. L. (2012). Openness and inconclusivity in interpretation in narrative inquiry: Dimensions of the social/personal. In E. Chan, V. Ross, \& D. Keyes (Eds.), Narrative inquirers in the midst of meaningmaking: Interpretive acts of teacher educators (pp. 1-22). Bingley, UK: Emerald Group Publishing Limited.

Richardson, V., \& Anders, P. (1994). The study of teacher change. In V. Richardson (Ed.), Teacher change and the development process: A case in reading instruction (pp. 159-180). New York: Teacher College Press.

Ross, V., \& Chan, E. (2008a). Multicultural education: Raj's story using a curricular conceptual lens of the particular. Teaching and Teacher Education, 24, 1705-1716.

Ross, V. \& Chan, E. (2008b). Schwab's call for a renaissance: A teacher education perspective. In L. F. Deretchin \& C. J. Craig (Ed.), Imagining a renaissance in teacher education: Teacher education yearbook XVI (pp. 4-24). Lanham, MD: Rowman \& Littlefield Education.

Rudduck, J., Chaplain, R., \& Wallace, G. (1996). School improvement: What can pupils tell us? London: David Fulton.

Schlein, C. (2010). Resonating effects of cross-cultural teaching. Curriculum and Teaching Dialogue, 12 (2), 153-175. 
Schlein, C., \& Chan, E. (2012). Considering culture in the interpretation of field texts. In E. Chan, V. Ross, \& D. Keyes (Eds.), Narrative inquirers in the midst of meaning-making: Interpretive acts of teacher educators (pp. 109-129). Bingley, UK: Emerald Group Publishing Limited.

Schlein, C., \& Chan, E. (2013). Examining students' experiences as a foundation for multicultural curriculum development. Journal of Curriculum Theorizing, 28 (2), 126-139.

Schwab, J. J. (1959/1978). Chapter 6: The "impossible" role of the teacher in progressive education. In I. Westbury \& N. J. Wilkof (Eds.), Science, curriculum, and liberal education: Selected essays (pp. 287-321). Chicago: University of Chicago Press.

Schwab, J. J. (1969). The practical: A language for curriculum. School Review, 78, 1-23.

Schwab, J. J. (1973). The practical 3: Translation into curriculum. School Review, $81,501-522$.

Schwab, J. J. (1983). The practical 4: Something for curriculum professors to do. Curriculum Inquiry, 13, 239-265.

Shulman, L. S. (1987). Knowledge and teaching: Foundations of the new reform. Harvard Educational Review, 57 (1), 1-22.

Shulman, L. S. (2004). The wisdom of practice: Essays on teaching, learning, and learning to teach. San Francisco: Jossey-Bass.

Tom, A. R., \& Valli, L. (1990). Professional knowledge for teachers. In R. Houston (Ed.), Handbook for research on teacher education: Project of the association of teacher educators (pp. 373- 392). New York: Macmillan Publishing Company.

Tsang, W. K. (2004). Teachers' personal practical knowledge and interactive decisions. Language Teaching Research, 8 (2), 163-198.

Tsui, A. (2004). Understanding expertise in teaching: Case studies of ESL teachers. TESOL Quarterly, 38 (1), 167-169.

Tsui, A. B. (2004). What teachers have always wanted to know-and how corpora can help. In J. M. Sinclair (Ed.), How to use corpora in language teaching (pp. 39-61). Amsterdam: John Benjamins Publishing.

Villegas, A. M. (1991). Culturally responsive pedagogy for the 1990's and beyond. Princeton, NJ: Educational Testing Service.

Whitehead, J., \& McNiff, J. (2006). Action research: Living theory. London: Sage Publications Ltd. 